\title{
The Case for Prebiotic Chemistry During the Hadean Eon
}

\author{
Rainer W. Kühne \\ Tuckermannstr. 35, 38118 Braunschweig, Germany \\ e-mail: kuehne70@gmx.de
}

\begin{abstract}
Geochemists disagree whether or not prebiotic chemistry has existed already during the Hadean Eon and whether the then terrestrial atmosphere has been strongly or weakly reduced. Here I argue that cellular life has existed already just after the end of the Hadean Eon and that terrestrial life has survived a number of cataclysms during the Earth's history. I argue that although organic molecules have been detected in meteorites that most organic molecules required for the formation of macromolecules must have been formed on Earth. Finally, I argue that the primitive terrestrial atmosphere during the Hadean Eon has been weakly reduced, so that amino acids and small nucleic acids could have been formed. I suggest that the first self-replicable macromolecules have been similar to viroids.
\end{abstract}

\section{Keywords}

Prebiotic chemistry, Late Heavy Bombardment, Hadean Eon, carbonaceous chondrites, primitive terrestrial atmosphere, viroids

\section{Geological History of the Earth}

According to a prominent scenario two protoplanets, called Gaia and Theia, collided 4.6 billion years ago and formed Earth and Moon [1]. Both planets, Earth and Moon, cooled and formed solid crusts. The oldest dated terrestrial rock is 4.03 billion years old and provides evidence of the then existence of continental crust [2].

Detrital zircons found in Jack Hills [3] and the Murchison District [4], both in Western Australia, and dated to be 4.4 billion years old provide evidence that the Earth had already then both a continental crust and a hydrosphere, i.e. oceans. Further examinations $[5,6]$ of theses zircons showed that the continental crust of the Hadean Eon (the time between 4.6 and 3.9 billion years ago) must have been recycled into the Earth's mantle.

The cataclysmic destruction of the terrestrial continental crust occurred 3.9 billion years ago during a period which became known as the Late Heavy Bombardment. It caused also a spike in the cratering rate on the Moon. According to a prominent scenario [7] the Late Heavy Bombardment resulted from the interactions of the planets Jupiter and Saturn with a disk of planetesimals. The resistance of the planetesimals resulted in a loss of orbital energy of Jupiter and Saturn, so that their orbital radii and orbital periods decreased. That of the innermost planet, Jupiter, decreased more rapidly than that of Saturn. As a consequence, the ratio of their orbital periods decreased. When the two planets crossed their mutual 1:2 mean motion resonance (the orbital period of Saturn became twice as large as that of Jupiter), their orbits became eccentric. This led to several close encounters among Saturn, Uranus, and Neptune. Moreover Jupiter strongly perturbed the asteroid belt. The result was a bombardment of both Earth and Moon with asteroids, which produced most of the craters and basins on the present surface of the Moon and the destruction of the terrestrial continental crust of the Hadean Eon.

It is probable that the water of the terrestrial oceans resulted from colliding comets [8]. This 
concerns both the water of the oceans of the Hadean Eon and the water of the Late Heavy Bombardment which formed the present oceans.

Geochemical evidence of biotic activity (photosynthesis) is provided by measurements of the carbon-isotope composition of carbonaceous inclusions within minerals from West Greenland which are 3.8 billion years old $[9,10]$.

Direct evidence for the earliest forms of life is provided by filamentous microfossils of up to more than 100 micrometers length in 3.2 to 3.5 billion years old deposits from the Pilbara Craton in Western Australia [11-13]. However, inorganic micrometer-sized filaments with helical morphology which consist of silica-coated carbonate crystal were synthesized. So it is not clear whether the filamentous forms from the Pilbara Craton are microfossils or inorganic crystals [14].

Terrestrial life survived a number of cataclysms. Glacial deposits in Namibia provide evidence of two ice ages during the late Proterozoic era, where the glaciation was global (so-called snowball Earth), except from open water in the equatorial belt. The first phase from 760 to 700 million years ago is termed the Sturtian ice age, while the second phase from 620 to 580 million years ago is termed the Varanger or Marinoan ice age. At least the second phase ended abruptly by strong volcanic eruptions and outgassing of large amounts of carbon dioxide $[15,16]$. The break-up of the continent Rodinia is assumed to have caused these ice ages [17].

Rapid cooling and glaciation occurred in the late Ordovician period 440 million years ago and was the probable cause of a mass extinction. It has been speculated that this rapid cooling was caused by a gamma-ray burst whose radiation depleted the terrestrial ozone layer [18].

The most dramatic extinction event occurred in the late Permian about 260 million years ago. It was caused either by an asteroid impact [19] or by strong volcanism [20].

Iridium concentrations detected within deep-sea limestones of the Cretaceous-Tertiary boundary 65 million years ago gave rise to the speculation that the extinction of the dinosaurs was caused by the impact of an asteroid with a diameter of ten kilometers [21]. This speculation was confirmed by the discovery of the Chicxulub crater on the Yucatan peninsula, Mexico [22]. Its size of 180 kilometers diameter was revealed by magnetic and gravity-field anomalies [22] and a cenote ring [23]. Its age was determined by argon analyses of melt rocks to be 65.2 million years [24].

On 30 June 1908 an object exploded at an altitude of about ten kilometers over Tunguska, Central Sibiria. Some authors speculated that this object was either a piece of anti-matter [25] or a black hole [26]. Comets and carbonaceous asteroids of the estimated energy of 10 to 20 megatons disrupt at too high altitudes, whereas iron objects reach and crater the terrestrial surface. The most plausible explanation is a stony asteroid of some 30 meters in radius [27] which disrupted into fragments which are no larger than ten centimeters [28].

According to geochemical evidence terrestrial life performed photosynthesis at least 3.8 billion years ago. Since then terrestrial life has survived several cataclysms including the Proterozoic glaciation (snowball Earth), the Ordovician glaciation, the Permian extinction event, and the impact of an asteroid at the Cretaceous-Tertiary boundary. In the following we will examine whether terrestrial life existed already during the Hadean Eon or whether it is of extraterrestrial origin (so-called panspermia hypothesis). 


\section{Organic Molecules in Meteorites}

The present terrestrial atmosphere consists mainly of nitrogen and oxygen. The primitive atmosphere during the Hadean Eon is assumed to have been strongly reduced and to have consisted of methane, ammonia, water, and hydrogen. In order to simulate lightning in this primitive Earth atmosphere, Stanley Miller circulated a hot mixture of methane, ammonia, water, and hydrogen in a flask and passed an electric discharge through the gas. He detected that the amino acids alanine and glycine had been generated [29].

Hydrogen as the lightest gas escapes from the upper atmosphere. So the atmosphere became weakly reduced. It is assumed that the atmosphere content of methane, ammonia, and hydrogen decreased, whereas the content of hydrogen cyanide and formaldehyde increased. The purine adenine [30, 31], amino acids [32], and peptides [33] were synthesized from concentrated hydrogen cyanide and water at moderate temperatures. As high concentrations of hydrogen cyanide are hardly imaginable in oceans and lakes (hydrogen cyanide is more volatile than water), it was suggested that the biochemical compounds were formed on comets and transported to the Earth [34]. This hypothesis was confirmed when amino acids were detected in the Murchison meteorite [35]. Also the purines adenine and guanine [36], xanthine, guanine, and hypoxanthine [37] were detected in the Murchison meteorite. Finally, the pyrimidine uracil was found in the Murchison, Murray, and Orgueil carbonaceous chondrites [38]. Polyols such as sugars and sugar alcohols were detected in the Murchison and Murray meteorites [39]. No ribose, no nucleotides, no peptides, and no proteins have been detected in meteorites.

By performing an electron probe microanalysis cellular structures, termed organized elements, of size between ten and thirty micrometers similar to unicellular organisms were detected in the Orgueil meteorite $[40,41]$. However, later it was shown that the organized elements were ragweed pollen (Ambrosia elatior) which were distorted by the applied Gridley method [42].

Within the martian meteorite ALH84001 which had been collected in the Allan Hills, Victoria Land, Antarctica there were detected structures which appeared to be unicellular organisms, except from the fact that the structures had a much smaller size, typically of the order of one hundred nanometers [43]. Later it was noticed that these structures were not martian nanofossils, but non-biological lamellar growth steps on pyroxene and carbonate crystals [44]. Nearly all amino acids of the meteorite are terrestrial in origin, although a low concentration of endogenous D-alanine cannot be excluded [45]. This negative result provides evidence against the hypothesis of panspermia [46] which states that a major fraction of the interstellar grains and comets consists of unicellular organisms.

As no ribose, nucleotides, peptides, proteins, RNA or unicellular organisms have been detected in meteorites, it is reasonable to investigate whether organic compounds can be synthesized under conditions of the primitive Earth.

\section{Prebiotic Chemistry Experiments}

The Stanley Miller experiment gained reputation when a number of amino acids were produced by later experiments which passed either electric discharges or ultraviolet light through mixtures of methane, ammonia, water, and hydrogen [47].

For example, methane was passed through an aqueous ammoniacal solution and the gas was heated during a subsequent passage through several solids such as silica gel, quartz 
sand and volcanic sand which are common in the crust of the Earth. By doing this the amino acids aspartic acid, threonine, serine, glutamic acid, proline, glycine, alanine, valine, alloisoleucine, isoleucine, leucine, tyrosine, and phenylalanine were produced [48].

A mixture of amino acids was placed in a depression of a heated piece of lava, where microparticles, which were later termed microspheres, with a typical size of one micrometer, were generated [49].

In experiments modeling volcanic or hydrothermal settings the amino acids phenylalanine, tyrosine, and glycine were converted into dipeptides and tripeptides by use of carbon monoxide, nickel sulphide, iron sulfide, and hydrogen sulphide as catalysts under aqueous conditions [50].

By contrast, present evidence does not support the synthesis of ribose under the conditions of the primitive Earth [51].

Experiments that simulate magmatic conditions and analysis of volatile condensates in volcanic gas show that volcanic activity can produce water-soluble polyphosphates [52].

Pyrimidine ribonucleotides were synthesized by using cyanamide, cyanoacetylene, glycolaldehyde, glyceraldehyde, and phosphate as starting materials. The formation of ribose and the nucleobase cytosine were bypassed. The four subsequent chemical reactions were:

(i) cyanamide + glycolaldehyde --> 2-amino-oxazole

(ii) 2-amino-oxazole + glyceraldehyde --> arabinose-amino-oxazoline

(iii) arabinose-amino-oxazoline + cyanoacetylene --> anhydroarabinonucleoside

(iv) anhydroarabinonucleoside + phosphate --> beta-ribocytidine-2',3'-cyclic phosphate

The last product is the cytidine nucleotide. The first three reactions were performed by using a phosphate buffer in a pH neutral solution [53].

The clay mineral montmorillonite is formed by aqueous weathering of volcanic ash. It was shown that this mineral catalyses the formation of oligomers of RNA that contain monomer units (nucleotides) of up to fifty [54].

These oligomers of RNA somewhat resemble the viroids. These are infectious pieces of free RNA which are not coated by proteins [55]. Later, viroids were shown to be singlestranded closed circular RNA molecules with a typical molecular weight of only 100,000 [56].

The failure to synthesize proteins and DNA under primitive terrestrial atmosphere conditions and the successful synthesis of amino acids, small peptides, purines, and pyrimidine ribonucleotides suggests the possibility of an RNA world [57, 58], i.e. a period during the Hadean Eon during which only RNA but no proteins and no DNA were synthesized [59].

\section{Conclusion}

Earth and Moon were formed 4.6 billion years ago by the collision of the two protoplanets Gaia and Theia. Afterwards the Earth formed a crust where colliding comets provided the water of the oceans. This Hadean Eon was terminated 3.9 billion years ago during the 
Late Heavy Bombardment when an eccentric orbit of Jupiter caused a bombardment of the Earth by asteroids. Soon thereafter, 3.8 billion years ago, there is geochemical evidence of terrestrial life which performed photosynthesis. The terrestrial life witnessed and survived several cataclysms including the snowball Earth 760 to 580 million years ago, an ice age 440 million years ago which was possibly caused by a gamma-ray burst, and an asteroid impact 65 million years ago which generated the Chicxulub crater and contributed to the extinction of the dinosaurs. The 1908 Tunguska explosion was caused by a small stony asteroid. Amino acids, purines, pyrimidines and sugars, but no proteins, nucleotides or extraterrestrial unicellular organisms were detected in meteorites. This argues against the hypothesis of panspermia. The synthesis of amino acids, small peptides, purines and pyrimidine ribonucleotides under conditions of the primitive Earth (Stanley Miller experiments) and the polymerization of RNA nucleotides on clay minerals suggests that viroids and an RNA world could have existed during the Hadean Eon.

\section{References}

[1] W. Benz, W. L. Slattery and A. G. W. Cameron, "The origin of the moon and the singleimpact hypothesis I", Icarus 66 (1986) 515-535.

[2] S. A. Bowring and I. S. Williams, "Priscoan (4.00-4.03 Ga) orthogneisses from northwestern Canada", Contributions to Mineralogy and Petrology 134 (1999) 3-16.

[3] S. A. Wilde, J. W. Valley, W. H. Peck and C. M. Graham, "Evidence from detrital zircons for the existence of continental crust and oceans on the Earth 4.4 Gyr ago", Nature 409 (2001) 175-178.

[4] S. J. Mojzsis, T. M. Harrison and R. T. Pidgeon, "Oxygen-isotope evidence from ancient zircons for liquid water at the Earth's surface 4,300 Myr ago", Nature 409 (2001) 178-181.

[5] E. B. Watson and T. M. Harrison, "Zircon thermometer reveals minimum melting conditions on earliest Earth", Science 308 (2005) 841-844.

[6] T. M. Harrison, J. Blichert-Toft, W. Müller, F. Albarede, P. Holden and S. J. Mojzsis, "Heterogeneous Hadean hafnium: evidence of continental crust at 4.4 to $4.5 \mathrm{Ga}$ ", Science 310 (2005) 1947-1950.

[7] R. Gomes, H. F. Levison, K. Tsiganis and A. Morbidelli, "Origin of the cataclysmic Late Heavy Bombardment period of the terrestrial planets", Nature 435 (2005) 466-469.

[8] C. F. Chyba, "The cometary contribution to the oceans of primitive Earth", Nature 330 (1987) 632-635.

[9] M. Schidlowski, "A 3,800-million-year isotopic record of life from carbon in sedimentary rocks", Nature 333 (1988) 313-318.

[10] S. J. Mojzsis, G. Arrhenius, K. D. McKeegan, T. M. Harrison, A. P. Nutman and C. R. L. Friend, "Evidence for life on Earth before 3,800 million years ago", Nature 384 (1996) 55-59.

[11] J. W. Schopf and B. M. Packer, "Early Archean (3.3-billion to 3.5-billion-year-old) microfossils from Warrawoona Group, Australia", Science 237 (1987) 70-73. 
[12] J. W. Schopf, "Microfossils of the Early Archean Apex Chert: new evidence of the antiquity of life", Science 260 (1993) 640-646.

[13] B. Rasmussen, "Filamentous microfossils in a 3,235-million-year-old volcanogenic massive sulphide deposit", Nature 405 (2000) 676-679.

[14] J. M. Garcia-Ruiz, S. T. Hyde, A. M. Carnerup, A. G. Christy, M. J. Van Kranendonk and N. J. Welham, "Self-assembled silica-carbonate structures and detection of ancient microfossils", Science 302 (2003) 1194-1197.

[15] P. F. Hoffman, A. J. Kaufman, G. P. Halverson and D. P. Schrag, "A Neoproterozoic snowball Earth", Science 281 (1998) 1342-1346.

[16] W. T. Hyde, T. J. Crowley, S. K. Baum and W. R. Peltier, "Neoproterozoic 'snowball Earth' simulations with a coupled climate/ice-sheet model", Nature 405 (2000) 425-429.

[17] Y. Donnadieu, Y. Godderis, G. Ramstein, A. Nedelec and J. Meert, "A 'snowball Earth' climate triggered by continental break-up through changes in runoff", Nature 428 (2004) 303-306.

[18] A. L. Melott, B. S. Lieberman, C. M. Laird, L. D. Martin, M. V. Medvedev, B. C. Thomas, J. K. Cannizzo, N. Gehrels and C. H. Jackman, "Did a gamma-ray burst initiate the late Ordovician mass extinction?", International Journal of Astrobiology 3 (2004) 55-61.

[19] L. Becker, R. J. Poreda, A. G. Hunt, T. E. Bunch and M. Rampino, "Impact event at the Permian-Triassic boundary: Evidence from extraterrestrial noble gases in fullerenes", Science 291 (2001) 1530-1533.

[20] P. B. Wignall, Y. Sun, D. P. G. Bond, G. Izon, R. J. Newton, S. Vedrine, M. Widdowson, J. R. Ali, X. Lai, H. Jiang, H. Cope and S. H. Bottrell, "Volcanism, mass extinction, and carbon isotope fluctuations in the Middle Permian of China", Science 324 (2009) 1179-1182.

[21] L. W. Alvarez, W. Alvarez, F. Asaro and H. V. Michel, "Extraterrestrial cause for the Cretaceous-Tertiary extinction", Science 208 (1980) 1095-1108.

[22] A. R. Hildebrand, G. T. Penfield, D. A. Kring, M. Pilkington, A. Camargo, S. B. Jacobsen and W. V. Boynton, "Chicxulub crater: a possible Cretaceous/Tertiary boundary impact crater on the Yucatan peninsula, Mexico", Geology 19 (1991) 867-871.

[23] K. O. Pope, A. C. Ocampo and C. E. Duller, "Mexican site for K/T impact crater?", Nature 351 (1991) 105.

[24] V. L. Sharpton, G. B. Dalrymple, L. E. Marin, G. Ryder, B. C. Schuraytz and J. UrrutiaFucugauchi, "New links between the Chicxulub impact structure and the Cretaceous/Tertiary boundary", Nature 359 (1992) 819-821.

[25] C. Cowan, C. R. Atluri and W. F. Libby, "Possible anti-matter content of the Tunguska meteor of 1908", Nature 206 (1965) 861-865.

[26] A. A. Jackson and M. P. Ryan, "Was the Tungus event due to a black hole?", Nature 
$245(1973) 88-89$.

[27] C. F. Chyba, P. J. Thomas and K. J. Zahnle, "The 1908 Tunguska explosion: atmospheric disruption of a stony asteroid", Nature 361 (1993) 40-44.

[28] V. V. Svetsov, "Total ablation of the debris from the 1908 Tunguska explosion", Nature 383 (1996) 697-699.

[29] S. L. Miller, "A production of amino acids under possible primitive Earth conditions", Science 117 (1953) 528-529.

[30] J. Oro and A. P. Kimball, "Synthesis of purines under possible primitive earth conditions. I. Adenine from hydrogen cyanide", Archives of Biochemistry and Biophysics 94 (1961) 217-227.

[31] J. Oro, "Mechanism of synthesis of adenine from hydrogen cyanide under possible primitive Earth conditions", Nature 191 (1961) 1193-1194.

[32] J. Oro and S. S. Kamat, "Amino-acid synthesis from hydrogen cyanide under possible primitive Earth conditions", Nature 190 (1961) 442-443.

[33] C. N. Matthews and R. E. Moser, "Peptide synthesis from hydrogen cyanide and water", Nature 215 (1967) 1230-1234.

[34] J. Oro, "Comets and the formation of biochemical compounds on the primitive Earth", Nature 190 (1961) 389-390.

[35] K. Kvenvolden, J. Lawless, K. Pering, E. Peterson, J. Flores, C. Ponnamperuma, I. R. Kaplan and C. Moore, "Evidence for extraterrestrial amino-acids and hydrocarbons in the Murchison meteorite", Nature 228 (1970) 923-926.

[36] R. Hayatsu, M. H. Studier, L. P. Moore and E. Anders, "Purines and triazines in the Murchison meteorite", Geochimica et Cosmochimica Acta 39 (1975) 471-488.

[37] W. van der Velden and A. W. Schwartz, "Search for purines and pyrimidines in the Murchison meteorite", Geochimica et Cosmochimica Acta 41 (1977) 961-968.

[38] P. G. Stoks and A. W. Schwartz, "Uracil in carbonaceous meteorites", Nature 282 (1979) 709-710.

[39] G. Cooper, N. Kimmich, W. Belisle, J. Sarinana, K. Brabham and L. Garrel, "Carbonaceous meteorites as a source of sugar-related organic compounds for the early Earth", Nature 414 (2001) 879-883.

[40] G. Claus and B. Nagy, "A microbiological examination of some carbonaceous chondrites", Nature 192 (1961) 594-596.

[41] B. Nagy, K. Frederiksson, H. C. Urey, G. Claus, C. A. Andersen and J. Percy, "Electron probe microanalysis of organized elements in the Orgueil meteorite", Nature 198 (1963) 121-125.

[42] F. W. Fitch and E. Anders, "Organized element: possible identification in Orgueil 
meteorite", Science 140 (1963) 1097-1100.

[43] D. S. McKay, E. K. Gibson, K. L. Thomas-Keprta, H. Vali, C. S. Romanek, S. J. Clemett, X. D. F. Chillier, C. R. Maechling and R. N. Zare, "Search for past life on Mars: possible relic biogenic activity in martian meteorite ALH84001", Science 273 (1996) 924930.

[44] J. P. Bradley, R. P. Harvey, H. Y. McSween, E. K. Gibson, K. L. Thomas-Keprta, H. Vali and D. S. McKay, "No nanofossils in martian meteorite", Nature 390 (1997) 454-456.

[45] J. L. Bada, D. P. Glavin, G. D. McDonald and L. Becker, "A search for endogenous amino acids in martian meteorite ALH84001", Science 279 (1998) 362-365.

[46] F. Hoyle and N. C. Wickramasinghe, "The case for life as a cosmic phenomenon", Nature 322 (1986) 509-511.

[47] S. L. Miller and H. C. Urey, "Organic compound synthesis on the primitive Earth", Science 130 (1959) 245-251.

[48] K. Harada and S. W. Fox, "Thermal synthesis of natural amino-acids from a postulated primitive terrestrial atmosphere", Nature 201 (1964) 335-336.

[49] S. W. Fox, "Thermal polymerization of amino-acids and production of formed microparticles on lava", Nature 201 (1964) 336-337.

[50] C. Huber and G. Wächtershäuser, "Peptides by activation of amino acids with CO on (Ni, Fe)S surfaces: implications for the origin of life", Science 281 (1998) 670-672.

[51] R. Shapiro, "Prebiotic ribose synthesis: A critical analysis", Origins of life and evolution of the biosphere 18 (1988) 71-85.

[52] Y. Yamagata, H. Watanabe, M. Saitoh and T. Namba, "Volcanic production of polyphosphates and its relevance to prebiotic evolution", Nature 352 (1991) 516-519.

[53] M. W. Powner, B. Gerland and J. D. Sutherland, "Synthesis of activated pyrimidine ribonucleotides in prebiotically plausible conditions", Nature 459 (2009) 239-242.

[54] J. P. Ferris, "Montmorillonite-catalysed formation of RNA oligomers: the possible role of catalysis in the origins of life", Philosophical Transactions of the Royal Society B 361 (2006) 1777-1786.

[55] T. O. Diener, "Potato spindle tuber "virus": IV. A replicating, low molecular weight RNA", Virology 45 (1971) 411-428.

[56] H. L. Sänger, G. Klotz, D. Riesner, H. J. Gross and A. K. Kleinschmidt, "Viroids are single-stranded covalently closed circular RNA molecules existing as highly base-paired rod-like structures", Proceedings of the National Academy of Sciences USA 73 (1976) 3852-3856.

[57] F. H. C. Crick, "The origin of the genetic code", Journal of Molecular Biology 38 (1968) 367-379. 
[58] L. E. Orgel, "Evolution of the genetic apparatus", Journal of Molecular Biology 38 (1968) 381-393.

[59] G. F. Joyce, "RNA evolution and the origins of life", Nature 338 (1989) 217-224. 